\title{
Development of cultivated and wild pomegranate mixed fruit jelly and its quality evaluation during storage
}

\section{N. S. Thakur, G. S. Dhaygude and Anshu Sharma*}

Department of Food Science and Technology (FST), Dr Yashwant SinghParmar University of Horticulture and Forestry, Nauni, Solan-173230 (Himachal Pradesh), INDIA

*Corresponding author. E-mail: anshufst1989@gmail.com

Received: July 5, 2016; Revised received: January 2, 2017; Accepted: February 23, 2017

\begin{abstract}
The present study was undertaken for the development of jelly from cultivated and wild pomegranate fruit juice mix and its quality evaluation during storage of six months. A product with $55 \%$ mixed fruit juice content (cultivated and wild pomegranate juice in 80:20 ratio) with $45 \%$ sugar was found to be the best on the basis of sensory analysis of prepared jelly. Jelly could safely be stored for a period of half year under both the ambient and refrigerated conditions without much change in its various chemical attributes viz., total soluble solids (TSS), titratable acidity, ascorbic acid, anthocyanins, pectin, total phenolics and sensory quality characteristics viz., colour, texture, flavour and overall acceptability. However, the changes in the quality characteristics of the jelly were slower in refrigerated storage conditions as compared to ambient conditions. Under refrigerated conditions, changes in TSS from 67.00 to $67.36^{0} \mathrm{~B}$,titratable acidity from 0.75 to $0.71 \%$, ascorbic acid from 9.18 to $7.35 \mathrm{mg} / 100 \mathrm{~g}$, anthocyanins from 11.34 to $10.17 \mathrm{mg} / 100 \mathrm{~g}$ and total phenols from 63.10 to $60.06 \mathrm{mg} / 100 \mathrm{~g}$ were observed after 6 months of storage. Both the packaging material viz., polyethylene terephthalate (PET) and glass jars were found suitable with comparatively slower changes occurring in glass jars under refrigerated conditions.
\end{abstract}

Keywords: Jelly, Packaging material, Storage, Wild pomegranate juice

\section{INTRODUCTION}

Pomegranate (Punica granatum L.) is a droughttolerant and long-lived plant. Arid and semiarid zones are popular for cultivation of pomegranate trees. They are widely cultivated in Iran, India and the Mediterranean countries such as Egypt, Turkey, Spain, Tunisia and Morocco (Ercisli et al., 2011). Its wild form is mainly distributed in Transcaucasia and Central Asia (Chandra et al., 2014). In India, pomegranate grows wild in certain regions of Western Himalaya which includes states like Himachal Pradesh, Jammu and Kashmir and Uttarakhand (Pandey et al., 2008; Narzary et al., 2009). Apart from enormous health benefits, this fruit also has potential to cure various diseases such as vomiting, sore eye, spinal cord troubles, bronchitis, liver, kidney and brain disorders (Jalikop et al., 2002). It was also observed that pomegranate could be used in the treatment of prostate cancer due to its ability to inhibit apoptosis (Rettig et al., 2008). Main reasons behind medicinal properties of Punica granatum L. are certain bioactive components such as polyphenols, anthocyanins and organic acids viz.,citric, malic,tartaric and succinic acid present in its juice content (Thakur et al., 2011; Chandra et al., 2014; Sharma and Thakur, 2016). It is believed that the antioxidant potential of pomegranate juice is more than that of red wine and green tea, which is induced through ellagitannins and hydrostable tannins (Zarfeshany et al., 2014).Traditionally, arils of wild pomegranates are utilized for preparation of dried condiment (anardana) because fresh arils of this fruit are quite tart in taste and mostly not liked by consumers due to its extremely acidic nature (Sharma and Thakur, 2016). The cultivated pomegranate fruits have been processed into various products like juice, juice concentrates, beverage, squash, frozen seeds, molasses, jam, wine, seeds in syrup, grenadine, pomegranate spirits, pomegranate powder, pomegranate rind powder, pomegranate seed oil and confectionery etc. (Dhinesh and Ramasamy, 2016). But only few scientific efforts have been put in direction of value addition of wild species of pomegranate fruits. Thus, looking upon the nutritional, medicinal characteristics of pomegranate fruit and increasing demand of value added products in urban market, the present study has been done to standardize the recipe for preparation of jelly from mixed fruit juice of cultivated and wild pomegranate along with storage study of the prepared product.

\section{MATERIALS AND METHODS}

Preparation of jelly: Fully mature cultivated and wild pomegranates i.e. yellowish green fruits harvested at 140-165 days after full bloom (DAFB) were procured 


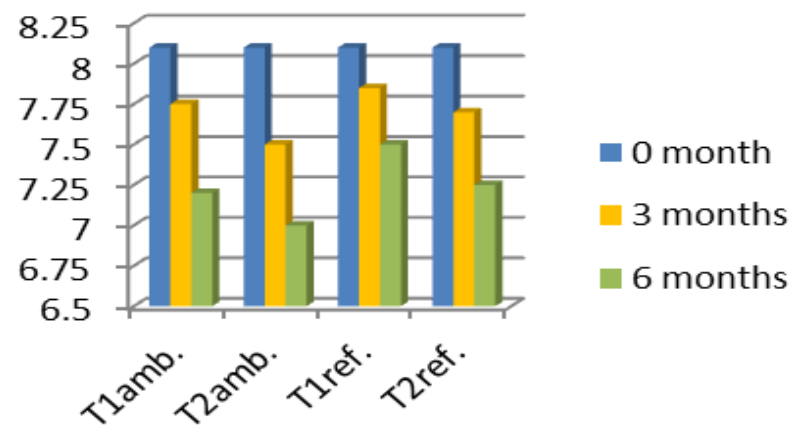

Fig. 1. Effect of different packaging treatments, storage conditions and intervals on colour scores of jelly.

from farmers of district Solan and brought to the FPR laboratory of the Department of Food Science and Technology, Dr. Yashwant Singh Parmar, University of Horticulture and Forestry, Nauni, Solan (HP). After washing of fruits, arils were extracted manually. A manual driven screw type juice extractor of Gardeners Corp, New Delhi make was used to extract juice from the freshly extracted arils of cultivated and wild pomegranate fruits, separately. Further, clarified juice was collected in a jar after filtration for jelly preparation.

Different combinations of wild pomegranate and commercial cultivated pomegranate juice were tried to develop a mixed fruit jelly at two levels

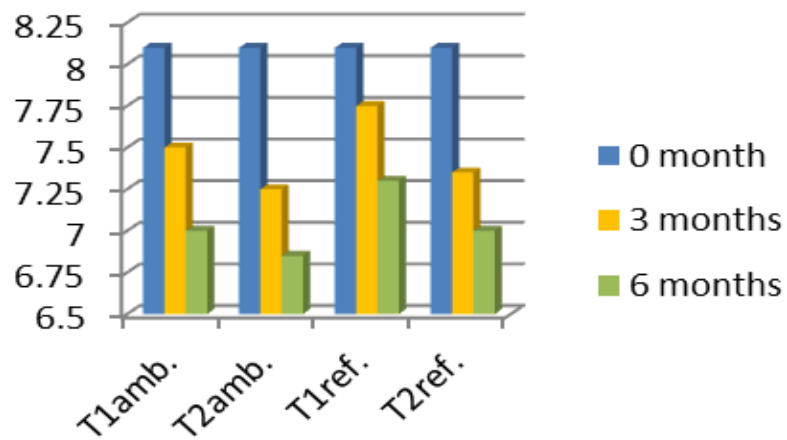

Fig. 2. Effect of different packaging treatments, storage conditions and intervals on texture scores of jelly.

of sugars as per details mentioned in Table 1. However, TSS of the product was kept constant at $67{ }^{0} \mathrm{~B}$. A known proportion of the mixture of juice of wild pomegranate and commercial pomegranate was cooked along with sugar to the desirable consistency when TSS of the product reached near to $67{ }^{0} \mathrm{~B}$. Pectin (1\%) was also added in all the treatment combinations during cooking. At the end of product preparation sodium benzoate (200 ppm) was mixed in the mixture as preservative. Jelly was filled hot into previously sterilized jars and allowed to cool at room temperature for proper setting.

Sensory and chemical analysis: After preparation

Table 1. Detail of recipes prepared from blend of commercial and wild pomegranate fruit juice for preparation of jelly.

\begin{tabular}{lllllllllc}
\hline Recipe symbol & & $\mathbf{R}_{\mathbf{1}}$ & $\mathbf{R}_{\mathbf{2}}$ & $\mathbf{R}_{\mathbf{3}}$ & $\mathbf{R}_{\mathbf{4}}$ & $\mathbf{R}_{\mathbf{5}}$ & $\mathbf{R}_{\mathbf{6}}$ & $\mathbf{R}_{\mathbf{7}}$ & $\mathbf{R}_{\mathbf{8}}$ \\
\hline \multirow{2}{*}{ Juice (\%) } & WP (\%) & 20 & 15 & 10 & 5 & 20 & 15 & 10 & 5 \\
Juice \% (WP + CV) & CV (\%) & 80 & 85 & 90 & 95 & 80 & 85 & 90 & 95 \\
Sugar (\%) & & 50 & 50 & 50 & 50 & 55 & 55 & 55 & 55 \\
\hline
\end{tabular}

WP: Wild pomegranate, CV: Commercial cultivar

Table 2. Sensory characteristics (scores on 9 point hedonic scale) of different recipes of jelly.

\begin{tabular}{lcccc}
\hline Treatment & Colour & Texture & Flavour & Overall acceptability \\
\hline $\mathrm{R}_{1}$ & 8.00 & 7.10 & 8.50 & 7.50 \\
$\mathrm{R}_{2}$ & 8.10 & 6.50 & 7.80 & 6.25 \\
$\mathrm{R}_{3}$ & 8.10 & 5.40 & 6.80 & 5.30 \\
$\mathrm{R}_{4}$ & 8.20 & 4.00 & 6.00 & 4.25 \\
$\mathrm{R}_{5}$ & 8.10 & 8.10 & 8.50 & 8.35 \\
$\mathrm{R}_{6}$ & 8.20 & 6.75 & 8.00 & 7.10 \\
$\mathrm{R}_{7}$ & 8.20 & 5.60 & 7.05 & 5.50 \\
$\mathrm{R}_{8}$ & 8.40 & 4.20 & 6.25 & 4.60 \\
$\mathrm{CD}$ & $\mathrm{NS}$ & 1.17 & 1.12 & 1.16 \\
\hline
\end{tabular}

Table 3. Effect of different packaging treatments, storage conditions and intervals on TSS ( $\left.{ }^{0} \mathrm{~B}\right)$ of jelly.

\begin{tabular}{|c|c|c|c|c|c|c|c|c|}
\hline \multirow{2}{*}{$\begin{aligned} \\
\end{aligned}$} & \multicolumn{3}{|c|}{ Ambient storage (Months) } & \multirow[b]{2}{*}{ Mean } & \multicolumn{3}{|c|}{ Refrigerated storage (Months) } & \multirow[b]{2}{*}{ Mean } \\
\hline & $\mathbf{0}$ & 3 & 6 & & $\mathbf{0}$ & 3 & 6 & \\
\hline $\mathrm{T}_{1}$ & 67.00 & 67.46 & 68.12 & 67.53 & 67.00 & 67.26 & 67.74 & 67.33 \\
\hline $\mathrm{T}_{2}$ & 67.00 & 67.58 & 68.46 & 67.68 & 67.00 & 67.36 & 67.80 & 67.39 \\
\hline Mean & 67.00 & 67.52 & 68.29 & 67.60 & 67.00 & 67.31 & 67.77 & 67.36 \\
\hline $\mathrm{CD}_{0.05}$ & \multicolumn{8}{|c|}{$\mathrm{T}=\mathrm{NS}, \mathrm{S}=0.31, \mathrm{~V}=\mathrm{NS}, \mathrm{T} \times \mathrm{S}=\mathrm{NS}, \mathrm{T} \times \mathrm{V}=\mathrm{NS}, \mathrm{S} \times \mathrm{V}=\mathrm{NS}$} \\
\hline
\end{tabular}

$\mathrm{T}=$ Packaging material, $\mathrm{S}=$ Storage period, $\mathrm{V}=$ Storage conditions, $\mathrm{T}_{1}=$ Glass jar, $\mathrm{T}_{2}=\mathrm{PET}$ jar 
N. S. Thakur et al. / J. Appl. \& Nat. Sci. 9 (1): 587 - 592 (2017)

Table 4. Effect of different packaging treatments, storage conditions and intervals on titratable acidity (\%) of jelly.

\begin{tabular}{|c|c|c|c|c|c|c|c|c|}
\hline \multirow{2}{*}{$\underset{T}{V} S$} & \multicolumn{3}{|c|}{ Ambient storage (Months) } & \multirow[b]{2}{*}{ Mean } & \multicolumn{3}{|c|}{ Refrigerated storage (Months) } & \multirow[b]{2}{*}{ Mean } \\
\hline & $\mathbf{0}$ & 3 & 6 & & $\mathbf{0}$ & 3 & 6 & \\
\hline $\mathrm{T}_{1}$ & 0.75 & 0.69 & 0.64 & 0.69 & 0.75 & 0.71 & 0.69 & 0.72 \\
\hline $\mathrm{T}_{2}$ & 0.75 & 0.67 & 0.65 & 0.69 & 0.75 & 0.70 & 0.67 & 0.71 \\
\hline \multirow[t]{2}{*}{ Mean } & 0.75 & 0.68 & 0.65 & 0.69 & 0.75 & 0.71 & 0.68 & 0.71 \\
\hline & \multicolumn{8}{|c|}{$\mathrm{T}=\mathrm{NS}, \mathrm{S}=0.03, \mathrm{~V}=\mathrm{NS}, \mathrm{T} \times \mathrm{S}=\mathrm{NS}, \mathrm{T} \times \mathrm{V}=\mathrm{NS}, \mathrm{S} \times \mathrm{V}=\mathrm{NS}$} \\
\hline
\end{tabular}

$\mathrm{T}=$ Packaging material, $\mathrm{S}=$ Storage period, $\mathrm{V}=$ Storage conditions, $\mathrm{T}_{1}=$ Glass jar, $\mathrm{T}_{2}=\mathrm{PET}$ jar

Table 5. Effect of different packaging treatments, storage conditions and intervals on ascorbic acid (mg/100 g) of jelly.

\begin{tabular}{|c|c|c|c|c|c|c|c|c|}
\hline \multirow{2}{*}{$\mathbf{V}$} & \multicolumn{3}{|c|}{ Ambient storage (Months) } & \multirow[b]{2}{*}{ Mean } & \multicolumn{3}{|c|}{ Refrigerated storage (Months) } & \multirow[b]{2}{*}{ Mean } \\
\hline & $\mathbf{0}$ & 3 & 6 & & $\mathbf{0}$ & 3 & 6 & \\
\hline $\mathrm{T}_{1}$ & 9.18 & 6.60 & 4.95 & 6.91 & 9.18 & 7.34 & 5.95 & 7.49 \\
\hline $\mathrm{T}_{2}$ & 9.18 & 6.02 & 4.25 & 6.49 & 9.18 & 7.00 & 5.40 & 7.20 \\
\hline \multirow[t]{2}{*}{ Mean } & 9.18 & 6.31 & 4.60 & 6.70 & 9.18 & 7.17 & 5.68 & 7.35 \\
\hline & \multicolumn{7}{|c|}{$\mathrm{T}=0.12, \mathrm{~S}=0.14, \mathrm{~V}=0.12, \mathrm{~T} \times \mathrm{S}=0.20, \mathrm{~T} \times \mathrm{V}=\mathrm{NS}, \mathrm{S} \times \mathrm{V}=0.20$} & \\
\hline
\end{tabular}

$\mathrm{T}=$ Packaging material, $\mathrm{S}=$ Storage period, $\mathrm{V}=$ Storage conditions, $\mathrm{T}_{1}=$ Glass jar, $\mathrm{T}_{2}=\mathrm{PET}$ jar

Table 6. Effect of different packaging treatments, storage conditions and intervals on anthocyanins (mg/100 g) of jelly.

\begin{tabular}{|c|c|c|c|c|c|c|c|c|}
\hline \multirow{2}{*}{$\underbrace{}_{T} \mathbf{S}$} & \multicolumn{3}{|c|}{ Ambient storage (Months) } & \multirow[b]{2}{*}{ Mean } & \multicolumn{3}{|c|}{ Refrigerated storage (Months) } & \multirow[b]{2}{*}{ Mean } \\
\hline & $\mathbf{0}$ & 3 & 6 & & 0 & 3 & 6 & \\
\hline $\mathrm{T}_{1}$ & 11.34 & 9.35 & 8.30 & 9.66 & 11.34 & 10.05 & 9.62 & 10.34 \\
\hline $\mathrm{T}_{2}$ & 11.34 & 8.95 & 7.75 & 9.35 & 11.34 & 9.55 & 9.12 & 10.00 \\
\hline \multirow[t]{2}{*}{ Mean } & 11.34 & 9.15 & 8.03 & 9.51 & 11.34 & 9.80 & 9.37 & 10.17 \\
\hline & \multicolumn{8}{|c|}{$\mathrm{T}=0.10, \mathrm{~S}=0.12, \mathrm{~V}=0.10, \mathrm{~T} \times \mathrm{S}=0.18, \mathrm{~T} \times \mathrm{V}=\mathrm{NS}, \mathrm{S} \times \mathrm{V}=0.18$} \\
\hline
\end{tabular}

$\mathrm{T}=$ Packaging material, $\mathrm{S}=$ Storage period, $\mathrm{V}=$ Storage conditions, $\mathrm{T}_{1}=$ Glass jar, $\mathrm{T}_{2}=$ PET jar

of different recipes of jelly, the best combination was selected on the basis of oraganoleptic analysis on 9 point hedonic scale for colour, texture, flavour and overall acceptability by a panel of 10 judges (Amerine et al., 1965). Further, selected samples of jelly were filled into glass and PET jars, sealed, tilted and stored at ambient and refrigerated temperature conditions for storage studies. The sensory analysis of stored samples of jelly at 0 day as well as at storage intervals of 3 and 6 months was also done at 9 point hedonic rating scale. Chemical characteristics of jelly were analyzed by standardized methods.

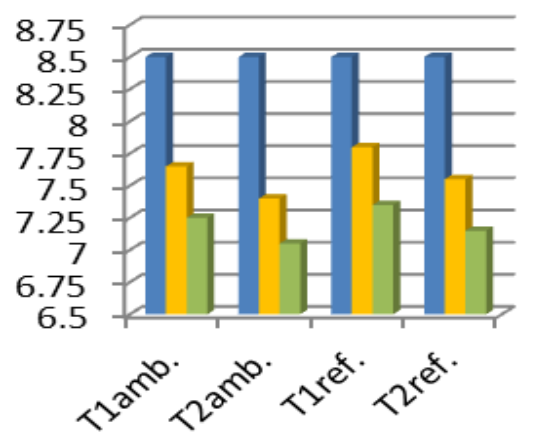

0 month

3 months

6 months

Fig. 3. Effect of different packaging treatments, storage conditions and intervals on flavour scores of jelly.
Hand refractometer was used to measure TSS of jelly and the results were expressed as degree Brix $\left({ }^{\circ} \mathrm{B}\right)$ or percentage (Ranganna, 2009). Titratable acidity and ascorbic acid (vitamin C) were determined as per AOAC (2004) methods and expressed conveniently in per cent (\%) citric acid and $\mathrm{mg} / 100 \mathrm{~g}$ of the sample, respectively. The total anthocyanins in $\mathrm{mg} / 100 \mathrm{~g}$ of sample were determined by the method given by Ranganna (2009). The total phenols were estimated by the Folin-Ciocalteu procedure given by Singleton and Fosssi (1965) and expressed in

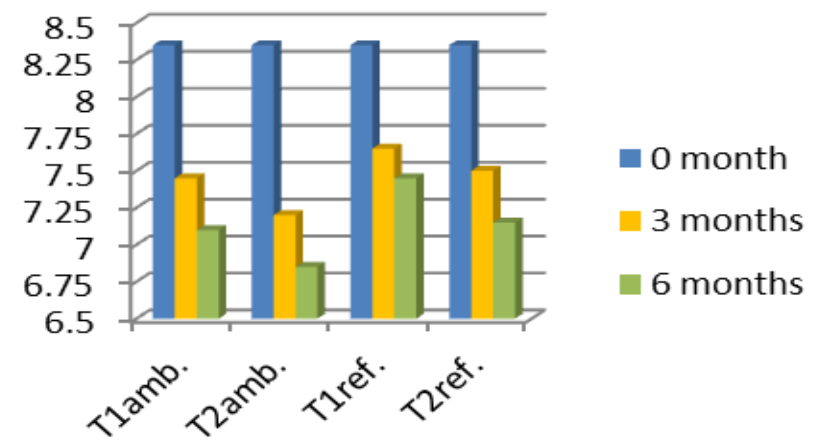

Fig. 4. Effect of different packaging treatments, storage conditions and intervals on overall acceptability scores of jelly. 
N. S. Thakur et al. / J. Appl. \& Nat. Sci. 9 (1): 587 - 592 (2017)

Table 7. Effect of different packaging treatments, storage conditions and intervals on pectin (\%) of jelly.

\begin{tabular}{|c|c|c|c|c|c|c|c|c|}
\hline $\mathbf{V}$ & \multicolumn{3}{|c|}{ Ambient storage (Months) } & \multirow[b]{2}{*}{ Mean } & \multicolumn{3}{|c|}{ Refrigerated storage (Months) } & \multirow[b]{2}{*}{ Mean } \\
\hline$T$ & $\mathbf{0}$ & 3 & 6 & & $\mathbf{0}$ & 3 & 6 & \\
\hline $\mathrm{T}_{1}$ & 1.18 & 0.98 & 0.94 & 1.03 & 1.18 & 1.02 & 0.98 & 1.06 \\
\hline $\mathrm{T}_{2}$ & 1.18 & 0.94 & 0.90 & 1.00 & 1.18 & 0.98 & 0.95 & 1.04 \\
\hline Mean & 1.18 & 0.96 & 0.92 & 1.02 & 1.18 & 1.00 & 0.97 & 1.05 \\
\hline
\end{tabular}

$\mathrm{T}=$ Packaging material, $\mathrm{S}=$ Storage period, $\mathrm{V}=$ Storage conditions, $\mathrm{T}_{1}=$ Glass jar, $\mathrm{T}_{2}=\mathrm{PET}$ jar

Table 8. Effect of different packaging treatments, storage conditions and intervals on total phenols $(\mathrm{mg} / 100 \mathrm{~g}) \mathrm{of}$ jelly.

\begin{tabular}{|c|c|c|c|c|c|c|c|c|}
\hline \multirow{2}{*}{$\underset{T}{V} S$} & \multicolumn{3}{|c|}{ Ambient storage (Months) } & \multirow[b]{2}{*}{ Mean } & \multicolumn{3}{|c|}{ Refrigerated storage (Months) } & \multirow[b]{2}{*}{ Mean } \\
\hline & $\mathbf{0}$ & 3 & 6 & & $\mathbf{0}$ & 3 & 6 & \\
\hline $\mathrm{T}_{1}$ & 63.10 & 58.85 & 56.81 & 59.59 & 63.10 & 60.34 & 58.07 & 60.50 \\
\hline $\mathrm{T}_{2}$ & 63.10 & 57.51 & 55.99 & 58.87 & 63.10 & 58.73 & 57.04 & 59.62 \\
\hline \multirow[t]{2}{*}{ Mean } & 63.10 & 58.18 & 56.40 & 59.23 & 63.10 & 59.53 & 57.55 & 60.06 \\
\hline & \multicolumn{7}{|c|}{$\mathrm{T}=0.43, \mathrm{~S}=0.53, \mathrm{~V}=0.43, \mathrm{~T} \times \mathrm{S}=0.75, \mathrm{~T} \times \mathrm{V}=\mathrm{NS}, \mathrm{S} \times \mathrm{V}=0.75$} & \\
\hline
\end{tabular}

$\mathrm{T}=$ Packaging material, $\mathrm{S}=$ Storage period, $\mathrm{V}=$ Storage conditions, $\mathrm{T}_{1}=$ Glass jar, $\mathrm{T}_{2}=\mathrm{PET}$ jar

$\mathrm{mg} / 100 \mathrm{~g}$ of jelly. For estimation of pectin per cent $(\%)$ in jelly, modified Carre and Haynes (1922) method as described by Ranganna (2009) was followed.

Statistical data analysis: The data pertaining to the sensory evaluation and chemical analysis of samples was analyzed by randomized block design (RBD) and completely randomized design (CRD), respectively. The experiments conducted in these studies were replicated thrice.

\section{RESULTS AND DISCUSSION}

From sensory scores mentioned in Table 2, it was concluded that recipe $\left(\mathrm{R}_{5}\right)$ with $55 \%$ mixed juice content containing $80 \%$ commercial variety juice and $20 \%$ wild pomegranate juice with $45 \%$ sugar was found to be best on the basis of sensory characteristics of jelly and was selected for further studies.

While studying the changes in jelly during storage (Table 3), a slight increase in TSS of wild pomegranate jelly was observed. The effect of storage period (S) on TSS of jelly reveals that it increased from 67.00 to 67.60 and $67.36{ }^{0} \mathrm{~B}$ under ambient and refrigerated conditions, respectively. However, less increase of TSS in refrigerated storage might be due to the slower rate of bio-chemical reactions at low temperature as compared to ambient storage conditions. The TSS of jelly increased non-significantly and this increase in TSS during storage might be due to conversion of polysaccharides into monosaccharide and soluble disaccharides (Gould, 1983). Our trend of results are in conformity with the findings of Kumar et al. (2007) in guava leather, Ahmed et al. (2011) in spota jam, Kuchi et al. (2014) in guava jelly bar and Sindumathi and Amutha (2014) in coconut based jam.

Gel firmness of jelly is dependent on per cent pectin along acidity of jelly. It is evident from the data given in Table 4 that there was a negligible decrease in acid content of jelly during entire storage period. The overall effect of storage period on the titratable acidity indicates that it decreased from 0.75 to 0.69 and $0.71 \%$ citric acid in jelly under ambient and refrigerated conditions, respectively. A decrease in titratable acidity of jelly might be due to co-polymerization of organic acids with sugars and amino acids. Similar trend of results were recorded by Paul et al. (2007) in guava jelly, Assis et al. (2007) in cashew apple jelly and Sundaram et al. (2007) in seabuckthorn mixed fruit jelly.

While going through data presented in Table 5 it was found that there was a decrease in ascorbic acid content of wild pomegranate jelly during storage. The effect of storage period (S), storage conditions (V) and packaging materials ( $\mathrm{T}$ ) on ascorbic acid content of jelly shows that it decreased with storage but retained more $(7.35 \mathrm{mg} / 100 \mathrm{~g})$ in refrigerated storage as compared to ambient conditions $(6.70 \mathrm{mg} / 100 \mathrm{~g})$ and further glass jar retained higher ascorbic acid and PET jar the lower during storage. Decrease in ascorbic acid content might be due to its degradation into dehydro-ascorbic acid or furfural during storage. Less decrease of ascorbic acid in refrigerated storage might be due to the slower rate of its degradation in low temperature as compared to ambient storage conditions because of its susceptibility to high temperature. Retention of higher ascorbic acid in glass jar may be due to the slower rate of reactions in glass jar as glass absorbs heat at slower rate as compared to PET jar during storage. The findings of the present studies are in agreement with the results reported by Assis et al. (2007) in cashew apple jelly, Sundaram et al. (2007) in seabuckthorn mixed fruit jelly, Sindumathi and Amutha (2014) in coconut based jam and Abolila et al. (2015) in orange based formulated low-calorie jam.

Anthocyanins not only act as potent antioxidants but 
also impart appealing red natural colour to pomegranate jelly. Infact, content of anthocyanin is proportional to the colour of jelly. Data in Table 6 reveals that there was a general decrease in anthocyanins of jelly during storage. However, its content retained more $(10.17 \mathrm{mg} / 100 \mathrm{~g})$ under refrigerated storage as compared to ambient conditions $(9.51 \mathrm{mg} / 100 \mathrm{~g})$. While, observing the overall effect of packaging on the anthocyanins of product, higher amount of anthocyanins were retained in glass jar and lower in PET jar. Loss of anthocyanins in jelly might be due to their high susceptibility to auto oxidative degradation during storage. More retention of this attribute in the product in refrigerated conditions as compared to ambient might be due to slower rate of auto oxidation of anthocyanins in refrigerated conditions. Retention of higher anthocyanins in glass jar may be due to the slower rate of reactions in glass as it absorbs heat at slower rate as compared to PET jar during storage. Similar findings were recorded by Sundaram et al. (2007) in seabuckthorn mixed fruit jelly.

Data presented in Table 7 indicate that there was a general decrease in pectin content of jelly during storage. The effect of storage period (S) on the pectin content of jelly shows that it decreased from 1.18 to 1.02 and $1.05 \%$ under ambient and refrigerated conditions, respectively. Possible reason for slight decrease in pectin content of wild pomegranate jelly may be due to hydrolysis of pectin into simple compounds. Our results are in confirmity to the findings of Paul et al. (2007) in guava jelly and Assis et al. (2007) in cashew apple jelly.

An appraisal of data (Table 8) reveals that there was a general decreasing trend in total phenols of fruit jelly during entire storage period of 6 months. While comparing effect of storage conditions $(\mathrm{V})$ on total phenol content, more $(60.06 \mathrm{mg} / 100 \mathrm{~g})$ phenols were retained under refrigerated conditions as compared to ambient conditions $(59.23 \mathrm{mg} / 100 \mathrm{~g})$. The overall effect of packaging materials $(\mathrm{T})$ indicates that higher phenols were retained in jelly packed in glass and lower in PET jar during storage. The decrease in total phenols in jelly during storage might be due to their involvement in the formation of polymeric compounds by complexing with protein and their subsequent precipitation as observed by Abers and Wrolstad (1979). As far as packaging material is concerned more retention of phenols in jelly packed in glass jar than PET jar might be due to the difference in their thermal conductance properties which affected internal decomposition reactions. Similar trend of decrease in total phenols have been reported by Sundaram et al. (2007) in seabuckthorn mixed fruit jelly and Assis et al. (2007) in cashew apple jelly.

There was a decrease in sensory scores viz., colour, texture, flavour and overall acceptability scores of jelly with the advancement of storage period (Fig. 1-4).
However, this decrease was within the acceptable limit (5-9 on 9 point hedonic) during whole storage period of 6 months. Decrease in scores was found significantly lower under refrigerated storage conditions than ambient conditions. As far as packaging effect is concerned, higher sensory scores of jelly were retained in the jelly packed in glass jar than PET jar. The decrease in sensory scores of product during storage might be due to degradation of anthocyanins, loss of sugar-acid blend and volatile aromatic compounds. Higher sensory scores in refrigerated storage conditions might be due to less degradation of pectin, slow biochemical reactions and degradation of anthocyanins as compared to ambient storage conditions which led the judges to award higher scores to the product in this condition. Trend of results for sensory scores are in conformity with the findings of Paul et al. (2007) in guava jelly, Sundaram et al. (2007) in seabuckthorn mixed fruit jelly, Touati et al. (2014) in apricot jam and Kuchi et al.(2014) in guava jelly bar.

\section{Conclusion}

Among all recipes, recipe $\left(\mathrm{R}_{5}\right)$ with $55 \%$ juice $(80 \%$ commercial variety juice $+20 \%$ wild pomegranate juice) with $45 \%$ sugar and a constant quantity of pectin was found to be the best on the basis of some sensory quality scores of jelly. Jelly packed in PET and glass jars could be stored for a period of six months under both the ambient and refrigerated conditions without much changes in various quality characteristics. However, the changes in the quality attributes of the jelly were slower under refrigerated storage as compared to ambient conditions.

\section{REFERENCES}

Abers, J. E. and Wrolstad, R. E. (1979). Causative factors of colour determination in strawberry preserves during processing and storage. Journal of Food Science, 44(1): $75-81$.

Abolila, R. M., Barakat, H., El-Tanahy, H. A. and El-Mansy, H. A. (2015). Chemical, nutritional and organoleptical characteristics of orange-based formulated low-calorie jams. Food and Nutrition Sciences, 6(13): 1229-1244.

Ahmed, T., Burhanuddin, M., Haque, M. A. and Hossain, M. A. (2011). Preparation of jam from sapota (Achras zapota). The Agriculturists, 9(1): 1-7.

Amerine, M. A., Pangborn, R. M. and Roessler, E. B. (1965). Principles of sensory evaluation of food. Academic Press, New York, N.Y., 559.

AOAC. (2004). Official Methods of Analysis of the Association of Official Analytical Chemists. 20th edn. Association of Official Analytical Chemists, Washington D.C.

Assis, M. M., Maia, G. A., Figueiredo, E. A. and Figuiredo, R. W. (2007). Processing and stability of cashew jelly. Revista cinecia Agronamica, 38(1): 46-51.

Carre, M. H. and Haynes, D. (1922). The estimation of pectin as calcium pectate and the application of this method to the determination of soluble pectin in apple. Journal of Biochemistry, 16(1): 60-69. 
Chandra, R., Pal, R. K., Deshmukh, R. and Suryavanshi, S. (2014). Genetic diversity of wild pomegranante (Punica granatum L.) distributed in Western Himalayas. Acta Biologica Indica, 3(2): 708-711

Dhinesh, K. V. and Ramasamy, D. (2016). Pomegranate processing and value Addition: Review. Journal of Food Procesing and Technology, 7(3):1-11

Ercisli, S., Gadze, J., Agar, G., Yildirim, N. and Hizarci, Y. (2011). Genetic relationships among wild pomegranate (Punica granatum) genotypes from coruh valley in Turkey. Genetics and Molecular Research, 10: 459-64

Gould, W. A. (1983). Tomato production, processing and quality evaluation. The Avi Publishing Company, West port, Connecticut.

Jalikop, S. H., Tiwari, R. B. and Kumar, S. (2002). Amlidana: a new pomegranate hybrid. Indian Horticulture, 21(3): 22-23

Kuchi, V. S., Gupta, R. and Vishwajith, K. P. (2014). Effect of packing materials on bio-chemical and organoleptic characteristics of guava jelly bar during storage. Environment and Ecology, 33(2): 800-803

Kumar, R., Jain, R. K. and Mandal, G. (2007). Storage stability of guava leather in different packing materials. Acta Horticulturae, 735: 621-65

Narzary, D., Mahar, K.S., Rana, T.S. and Ranade, S.A. (2009). Analysis of genetic diversity among wild pomegranate in western Himalayas using PCR methods. Scientia. Horticulturae, 121: 237-242

Pandey, A., Tomer, A. K., Bhandari, D. C. and Pareek, S. K. (2008). Towards collection of wild relatives of crop plants in India. Genetic Resources and Crop Evolution, 55: $187-202$

Paul, S. E., Chakrabarty, S., Jana, S. C., Hasan, M. A., Mandal, K.K., Sarkar, S.S. and Mazumdar, D. (2007). A multivariate approach to study the sensory parameters of guava jelly on the basis of physico-chemical parameters of guava fruits. Acta Horticulture, 735: 561-568

Ranganna, S. (2009). Handbook of analysis and quality control for fruit and vegetable products. Tata McGraw Hill, New Delhi, 1112

Rettig, M. B., Heber, D., An, J., Seeram, N. P., Rao, J. Y. and Liu, H. (2008). Pomegranate extract inhibits androgen-independent prostate cancer growth through a nuclear factor-kappa B-dependent mechanism. Molecular Cancer Therapeutics, 7(9):2662-2671

Sharma, A.and Thakur, N. S. (2016). Influence of active packaging on quality attributes of dried wild pomegranate (Punica granatum L.) arils during storage. Journal of Applied and Natural Science, 8(1): 398 - 404

Sindumathi, G. and Amutha, S. (2014). Processing and quality evaluation of coconut based jam. Journal of Environmental Science, Toxicology and Food Technology, 8(1): 10-14

Singleton, V. L. and Rossi, J. A. (1965). Colorimetry of total phenolics with phosphomolybedic phosphotungstic acid reagents. American Journal of Enology and Viticulture, 16: $144-158$

Sundaram, Minakshi, S., Iarahath, K. and Bawa, A. S. (2007). Development of seabuck thorn mixed fruit jelly. International Journal of Food Science and Technology, 42(4): 403-410.

Thakur, N. S., Dhaygude, G. S. and Gupta, A. (2011). Physico-chemical characteristics of wild pomegranate fruits in different location of Himachal Pradesh. International Journal of Farm Science, 1(2): 37-44

Touati, N., Tarazona-Diaz M. P., Aquayo, E., and Louaileche, H. (2014). Effect of storage time and temperature on the physicochemical and sensory characteristics of commercial apricot jam. Food chemistry, 145: 23-27

Zarfeshany, A., Asgary, S. and Javanmard, S. H. (2014) Potent health effects of pomegranate. Advanced Biomedical Research, 3: 100 